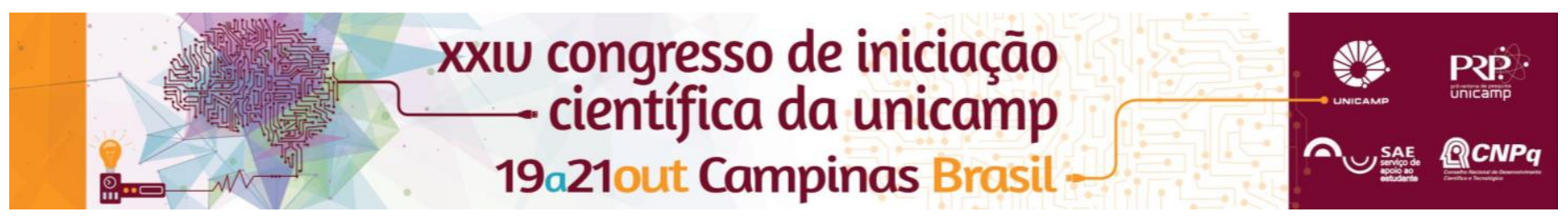

\title{
Conjugados da Reação de Maillard como agentes encapsulantes: produção e aplicação em emulsões
}

\author{
Ramonita A. O. Dias*, Larissa Consoli, Míriam D. Hubinger
}

\begin{abstract}
Resumo
Proteínas e carboidratos, quando aquecidos em um mesmo meio, formam novos produtos a partir da Reação de Maillard. O presente projeto teve como principal objetivo o estabelecimento de condições de processo para a obtenção de conjugados da Reação de Maillard por via úmida, a partir de misturas entre caseinato de sódio, maltodextrina e xarope de glicose, a fim de utilizar estes produtos como agentes encapsulantes. O processo ocorreu a $75{ }^{\circ} \mathrm{C}$, por 24 horas, sendo coletadas amostras para análise ao longo de todo o período. Os produtos foram caracterizados quanto à cor, potencial zeta, perfil eletroforético e tensão interfacial.
\end{abstract}

\section{Palavras-chave: conjugados proteína-polissacarídeo, capacidade emulsificante, eletroforese}

\section{Introdução}

A Reação de Maillard é uma reação de escurecimento não enzimático entre açúcares redutores e compostos que possuem grupos amina livres, como as proteínas. Em alimentos como chocolates, doces e produtos de panificação, a Reação de Maillard pode gerar compostos que conferem cor e sabor aos produtos. Outro efeito bastante importante desta reação é que a conjugação entre proteínas e carboidratos (polissacarídeos ou açúcares pequenos) pode melhorar as propriedades funcionais das proteínas, como a emulsificante e estabilizante ${ }^{1}$. Deste modo, o objetivo deste trabalho foi estabelecer uma metodologia para a produção de conjugados da Reação de Maillard a partir de caseinato de sódio, maltodextrina, e xarope de glicose em via úmida, e posterior aplicação como agente emulsificante.

\section{Resultados e Discussão}

A produção dos conjugados de Maillard a partir de caseinato de sódio, maltodextrina e xarope de glicose aconteceu em soluções aquosas. Antes de iniciar a reação, cada componente foi solubilizado individualmente, sob agitação, overnight. Logo após, foram misturados e mantidos à temperatura de $75^{\circ} \mathrm{C}$ durante 24 horas, sendo coletadas alíquotas nos tempos de 0, 3, 6, 9, 12 e 24 horas. Os produtos foram analisados com relação à cor, potencial zeta, perfil eletroforético e tensão interfacial.

A análise de cor dos conjugados proteína-polissacarídeo confirmou o escurecimento das amostras ao longo do tempo de reação. Essa alteração de cor foi comprovada pelos parâmetros $L^{*}$ e pela cromaticidade medida por $a^{*} e$ $b^{*}$. O parâmetro $L^{*}$ caiu com o passar do tempo, indicando escurecimento. Os parâmetros $a^{*}$ e $b^{*}$ apresentaram aumento, devido às amostras mais avermelhadas e amareladas, respectivamente.

Observou-se que, para mesmos valores de $\mathrm{pH}$, os produtos da reação de Maillard apresentaram, em geral, cargas com maior valor em módulo. Isto ocorreu principalmente nas amostras obtidas nos tempos iniciais de reação, demonstrando a maior estabilidade dos conjugados em relação à proteína pura.

O perfil eletroforético das amostras revelou bandas de alfa e beta caseína mais intensas no começo da reação, indicando a presença de caseína pura na amostra. Com o passar do tempo de reação, a intensidade destas bandas diminuiu, demonstrando a ligação que ocorreu entre a proteína e o carboidrato². A análise também mostrou bandas polidispersas e mais intensas, que sugerem a formação de materiais de massa molecular superior ${ }^{3}$.

A medida de tensão interfacial entre os conjugados e óleo de palma mostrou que as amostras coletadas em todos os tempos de reação atingiram, no equilíbrio, tensões interfaciais muito próximas $(\sim 5 \mathrm{mPa})$. No entanto, o tempo para estabilização da tensão interfacial diminuiu conforme o tempo de reação aumentou (Figura 1). Isso ressalta o potencial do uso dos produtos da Reação de Maillard como emulsificantes em emulsões óleo em água.

Figura 1. Tensão interfacial entre os conjugados proteínapolissacarídeo e óleo de palma $\left(50^{\circ} \mathrm{C}\right)$.

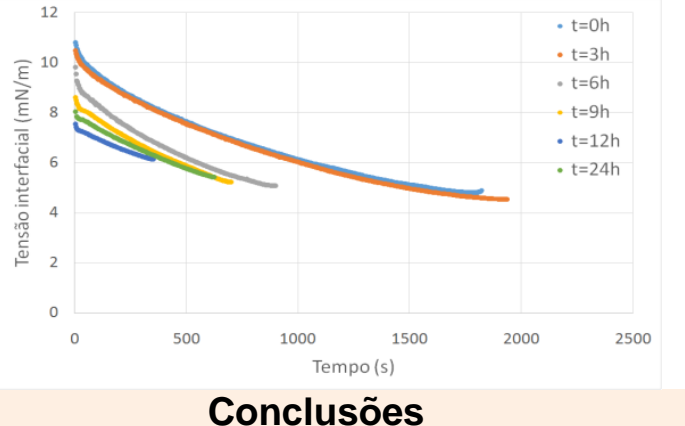

A partir do exposto neste trabalho, pode-se confirmar que a condição de processo estudada possui alto potencial para a produção de conjugados da Reação de Maillard, os quais apresentam características bastante favoráveis para a obtenção de emulsões estáveis.

\section{Agradecimentos}

Os autores agradecem à FAPESP (2015/ 11984-7) pelo apoio financeiro e CNPQ pelas bolsas de Iniciação Cientifica e Doutorado.

(1)OLIVER, C. M.; MELTON, L.; STANLEY, R.CreatingProteins with Novel Functionality via the Maillard Reaction: A Review, Critical Reviews in FoodScience and Nutrition, 46:4, 337-350, 2006.

(2)BARBOSA, J. M. Capacidade emulsificante de conjugados de caseinato de sódio-goma jataí produzidos pela reação de Maillard. Campinas, SP, 2013 (Dissertação de Mestrado). Universidade Estadual de Campinas, 2013.

(3)KATO, A.; MIFURU, R.; MATSUDOMI, N. \& KOBAYASHI, K. Functional Casein-Polysaccharide Conjugates Prepared by Controlled Dry Heating.Bioscience, Biotechnology, and Biochemistry, pp. 567-571, 2014. 